\title{
APRENDENDO COM OS ERROS DOS OUTROS: O QUE A HISTÓRIA DA CIÊNCIA POLÍTICA AMERICANA TEM PARA NOS CONTAR
}

\author{
João Feres Jr. \\ City University of New York
}

\begin{abstract}
RESUMO
Este artigo pretende mostrar que a análise da história da Ciência Política americana pode nos ajudar a pensar criticamente as Ciências Sociais no Brasil. A versão historiográfica dominante, representada por John Gunnell e outros, ignora o papel ideológico e antidemocrático que a Ciência Política behaviorista assumiu durante a Guerra Fria, enquanto histórias mais críticas são mantidas à margem da disciplina. Essa situação espelha o arranjo institucional da própria Ciência Política, que promove o isolamento da subárea de teoria política das outras sub-áreas mais "cientificas".
\end{abstract}

PALAVRAS-CHAVE: história da Ciência Política; Ciência Política americana; teoria política; Guerra Fria; positivismo; revolução comportamentalista.

"We have a practical task of world education in the American way of life and in the spirit of American government, made in its image".

Leonard D. White, cientista político

\section{INTRODUÇÃO}

O que a história da Ciência Política americana pode ensinar aos cientistas sociais brasileiros? Essa é a questão de fundo que orienta este artigo. Como a maioria das questões de que se ocupam as Ciências Humanas, essa também não tem uma resposta simples. Não há "uma" história da Ciência Política americana, mas de fato várias narrativas que diferem de maneira significativa entre si. É exatamente do embate entre essas versões que podemos aprender algumas lições esclarecedoras que talvez nos ajudem a melhor compreender o passado e o presente, e a projetar o futuro das Ciências Sociais no Brasil, assim como a pensar as relações entre Ciências Sociais, democracia e republicanismo em nosso país.

\section{ANATOMIA DA PROFISSÃO}

A Ciência Política é uma invenção americana. Apesar de aparentemente exagerada, essa afirmação é em boa medida verdadeira. Claro que a idéia de um esforço sistemático de compreensão da política é coisa bem mais antiga. O Platão das Leis e Aristóteles são candidatos óbvios ao título de fundadores desse tipo de reflexão. Desde então uma horda de pensadores sucedeu-os: gregos, romanos, italianos, espanhóis, ingleses, franceses etc. Em suma, a invenção do estudo sistemático da política não pode ser atribuída aos americanos. O que estes fizeram, de fato, foi criar uma profissão acadêmica especializada no estudo da política e institucionalmente separada do estudo da História e da Filosofia. Mais tarde essa disciplina se diferenciaria também da Sociologia, da Psicologia e da Antropologia.

A institucionalização da Ciência Política americana, na prática, correspondeu à criação de empregos, cursos, departamentos, programas, centros de pesquisa, revistas especializadas, associações e linhas de financiamento de pesquisa sob o mesmo rótulo disciplinar da Ciência Política. Paralelo a esse processo de desenvolvimento institucional ocorreu um movimento de especialização. A estrutura institucional da Ciência Política americana é hoje dividida em cinco sub-áreas: política americana, política comparada, relações internacionais, políticas públicas e teoria política. Cada sub-área apresenta um alto grau de autonomia 
disciplinar e endogenia. Conseqüentemente, um professor de política comparada, por exemplo, só ensina cursos de política comparada, publica em periódicos especializados em política comparada, e participa de conferências nas mesas e painéis da mesma sub-área.

Tal nível de especialização acadêmica não foi igualado até hoje por nenhum outro país do mundo. Mesmo no Brasil, onde a academia caminha a passos largos em direção ao modelo americano, a Ciência Política não é muito institucionalizada. Muitas universidades preferem ter programas de doutorado em Ciências Sociais; não há periódico algum especializado em Ciência Política, quanto mais em alguma sub-área da disciplina; e a recémcriada Associação Brasileira de Ciência Política é quase 100 anos mais nova e 100 vezes menor que sua irmã americana.

Em parte, por ter sido vanguarda na criação da Ciência Política, a academia americana tornouse modelo para os departamentos de Ciência Política em outros países e pólo exportador de tendências teóricas e temáticas. A influência da Ciência Política americana no mundo também se dá por meio da formação de acadêmicos de outros países nos inúmeros programas de doutorado em Ciência Política dos EUA. O fato de a maioria dos bolsistas brasileiros no exterior que fazem doutorado em Ciência Política estarem alocados em universidades americanas é evidência clara dessa influência. Ou seja, o contribuinte brasileiro tem financiado essa "importação" de "conhecimento". Nada mais razoável, portanto, do que aperfeiçoarmos nossa apreciação crítica da história e papel político desse produto no seu lugar de produção original.

\section{A HISTÓRIA "OFICIAL"}

O uso da expressão "Ciência Política" já era corrente nos EUA ao final do século XVIII, durante a guerra de libertação-que os americanos chamam sem ironia alguma de "revolução" - e, principalmente, durante os debates entre federalistas e anti-federalistas, que precederam a ratificação da Constituição americana. De acordo com James Farr, nesse contexto a expressão era usada de maneira retórica por escritores de diferentes orientações políticas. Em outras palavras, seu significado era vago e aberto à contestação. John Adams, o segundo presidente americano, falou da "divina Ciência Política". Alexander Hamilton, um dos autores de $O$ federalista, usou a expressão para glorificar o progresso da Ciência Política em vista das novas experiências institucionais postas em prática pelo recém-criado governo americano. James Madison, outro importante federalista e quarto presidente dos EUA, via a Ciência Política como instrumento fundamental de correção institucional e aprimoramento da governança (FARR, 1993).

A entrada da Ciência Política no ambiente acadêmico ocorreu somente sete décadas após os debates sobre a Constituição. Em 1857, o imigrante alemão Fancis Lieber foi nomeado catedrático em História e Ciência Política pela Universidade de Columbia, o primeiro posto desse tipo a ser criado na academia americana. Em 1880, na mesma universidade, foi criado o primeiro departamento de Ciência Política, sob a direção de John W. Burgess. Finalmente, em 1903, a Associação Americana de Ciência Política (APSA) se consolidou.

Farr declara que muitos cientistas políticos americanos do século XIX, entre eles Lieber, Burguess e Woodrow Wilson, entendiam que sua tarefa era eminentemente pedagógica e política, qual seja, ensinar aos cidadãos americanos as virtudes republicanas. "O fim do século XIX foi um período de vitalidade e fertilidade para a ciência americana da política, que proclamou sua identidade e unidade como a ciência do Estado. Ao promover a educação dos cidadãos, ao mesmo tempo que a teorização científica, a disciplina tornou-se mais profissional e inteiramente acadêmica" (FARR, 1988).

Farr parece não ver uma contradição insolúvel no fato de a ciência americana ter sido, no século XIX, uma "ciência do Estado" ao mesmo tempo que uma atividade dedicada à educação política dos cidadãos. Isso porque, seguindo seu raciocínio, o Estado americano, por ser democrático, estaria naturalmente interessado na promoção dessa educação republicana. De fato, a vocação democrática da Ciência Política americana é tomada por Farr, e por muitos outros historiadores da Ciência Política naquele país, como um dado histórico inquestionável. Após defender a idéia de que a história da Ciência Política americana deveria ser estudada dando prioridade à relação entre Ciência Política e política, Farr conclui que entre todas as diversas atividades que definem o exercício da Ciência Política, a "educação dos cidadãos para a democracia" é historicamente predominante. Segundo Farr, o apego à democracia une cientistas políticos 
de todas as gerações (idem). Para reforçar essa convicção, o autor cita a seguinte passagem de autoria de Erkki Berndtson: "A Ciência Política apareceu com o crescimento da democracia representativa. A conclusão lógica a ser tirada é que o desenvolvimento da Ciência Política, da maneira pela qual a entendemos, depende do futuro da democracia representativa" (ANCKAR \& BERNDTSON, 1987).

Contudo, a história da vocação democrática da Ciência Política americana tem também os seus percalços. Farr lamenta que o comprometimento republicano da Ciência Política tenha se deteriorado devido à excessiva profissionalização da disciplina. Para o autor, o inchamento do sistema universitário e a autonomia dos critérios acadêmicos de promoção e sucesso profissional levaram o cientista político para longe da política. Ao invés de se envolverem na solução dos problemas concretos da democracia americana, os cientistas políticos cada vez mais passam seu tempo discutindo entre si teorias com pouca relevância prática.

Esse veredicto é repetido de maneira similar por outros autores. Em um livro de título sugestivo, The Tragedy of Political Science. Politics, Scholarship and Democracy, David Ricci afirma que a Ciência Política americana tem se dedicado, através de suas teorias e engajamento político, à transmissão e à compreensão dos valores democráticos (RICCI, 1984). A tragédia fica por conta da interação histórica entre o projeto científico e as aspirações democráticas. Segundo Ricci, o rigor do procedimento científico levou os cientistas políticos americanos a descobrirem "fatos reais" que contradizem os valores democráticos, como, por exemplo, que o sistema político americano é sustentado pela indiferença dos cidadãos e não por seu engajamento político. Além disso, a demanda por factualismo e a rejeição de julgamentos de valor têm por conseqüência o abandono de questões normativas importantes para a saúde democrática, como a virtude política e o patriotismo. A profissionalização também contribuiu para o estranhamento entre o exercício da Ciência Política e sua vocação, ao afastar do escopo dos estudos acadêmicos as questões políticas mais controversas e debatidas. Em suma, o quadro pintado por Ricci se assemelha ao de Farr: uma vocação democrática problematizada por um profissionalismo alienante que, apesar de não ameaçar aquela convicção, é a causa principal de uma crise de falta de relevância política.

Raymond Seidelman e Edward J. Harpham também seguem um script parecido. Em um estudo centrado nas contribuições individuais de dez dos cientistas políticos mais influentes no período de Constituição da academia americana, Seidelman e Harpham identificam uma tradição de engajamento político desses intelectuais com questões relativas à reforma progressista das instituições democráticas. Contudo, geração após geração, esses intelectuais viram seus projetos de reforma rejeitados pelas instituições políticas dos EUA. Em resposta a essa rejeição, os cientistas políticos passaram a incrementar o rigor científico de suas teorias na esperança de adquirirem maior aceitação e autoridade social e, conseqüentemente, maior cacife político. Segundo os autores, essa tática teve resultados infelizes, pois acabou por afastar os cientistas políticos do problemas mais candentes da democracia americana, e encerrá-los em uma comunidade autocentrada e estanque. De novo, a narrativa se repete: a inspiração democrática da Ciência Política mantém-se mas sua eficácia prática é prejudicada pelo excessivo enquistamento profissional.

A defesa mais ardente da identidade entre Ciência Política e democracia é feita for David Easton, John G. Gunnell e Michael Stein no livro Regime and Discipline: Democracy and the Development of Political Science, editado pelos mesmos autores (EASTON \& GUNNELL, 1995). Easton e Stein fundaram em 1985 o Comitê Internacional para o Estudo do Desenvolvimento da Ciência Política (ICSDPS), que é afiliado à Associação Internacional de Ciência Política (IPSA). Esse comitê promoveu três encontros internacionais, em Cortona (Itália), Barcelona e Paris, para discutir a história e o desenvolvimento da Ciência Política em diferentes nações do mundo. O livro é uma coletânea de textos produzidos durante esses encontros e selecionados de maneira a dar grande relevância ao papel fundador da Ciência Política americana. A questão que supostamente orienta o projeto de Regime and Discipline é a da relação causal "recíproca" entre Ciência Política e regime político. No texto introdutório do livro, Easton, Gunnell e Stein começam por afirmar que a Ciência Política é uma invenção americana, para logo depois dizer que, historicamente, a Ciência Política esteve tão intimamente ligada à democracia que ela é às vezes chamada de "ciência da democracia"; os autores concluem que em países democráticos 
a Ciência Política é mais desenvolvida porque "[...] o estabelecimento de instituições democráticas ajuda a fomentar um clima político e cultural mais propício ao aparecimento da Ciência Política como disciplina, e a disciplina, em si, pode contribuir para a instituição e posterior evolução da democracia em um dado país. Isso porque a Ciência Política como disciplina está mais apta a florescer em um contexto liberal de discussão e crítica, controle estatal limitado, e desenvolvimento profissional autônomo. O cientista político profissional, por sua vez, se inclina a promover ativamente regimes que proporcionam tais condições" (idem).

Descontando a repetição e circularidade dos argumentos na passagem acima, devemos notar o tom de universalidade com o qual os autores se referem às leis do desenvolvimento da Ciência Política. Contudo, o que está sendo de fato universalizada é a compreensão que esses autores têm da história da Ciência Política em seu próprio país, os EUA. Uma compreensão que beira a autoadulação. Coerentemente, em uma passagem posterior, os mesmos autores igualam o desenvolvimento da Ciência Política à emulação do modelo americano. Pairando sobre esse raciocínio está a premissa de que a democratização também corresponde à implantação do modelo liberaldemocrático americano.

Em textos escritos sem a colaboração dos outros dois colegas, John Gunnell apresenta uma narrativa mais acabada da história da Ciência Política americana. De acordo com esse autor, a Ciência Política americana era umbilicalmente ligada à democracia desde sua fundação, em meados do século XIX. Nesse contexto não havia divisão entre ciência e teoria, como hoje há, e os profissionais da disciplina se dedicavam à crítica construtiva e ao avanço das instituições democráticas daquele país. Segundo Gunnell, a tradição da Ciência Política nos EUA deve ser entendida como uma tentativa de substituir a religião, como fator de coesão social, por uma ciência de controle social e políticas públicas que promovesse os valores liberais. Ou seja, como Farr, ele não vê contradição em um projeto que vise ao controle social e à educação cívica liberal. Contudo, esse idílio entre Ciência Política e democracia sofreu um grave abalo por volta da Segunda Guerra Mundial.

Os causadores desse abalo foram os intelectuais judeus alemães que imigraram para os EUA na década de 30, fugindo do nazismo na Europa. Gunnell lembra que, apesar de suas diferenças ideológicas, tanto Leo Strauss como Eric Voeglin, Hannah Arendt e Herbert Marcuse foram críticos severos do liberalismo americano. Todos viam na neutralidade em relação aos valores pregada pela Ciência Política empiricista americana uma forma de relativismo moral absoluto e, portanto, um passo certeiro em direção ao totalitarismo (GUNNELL, 1988).

Gunnell defende que os intelectuais imigrantes erraram gravemente em sua avaliação. Primeiro, porque sua experiência traumática com o totalitarismo na Europa os fez projetar essa ameaça no contexto dos EUA, onde não havia risco de degeneração totalitária. Segundo, porque seu modo de pensar estava impregnado de questões filosóficas, epistemológicas e universais que os impedia de compreender o pragmatismo na orientação da Ciência Política americana. Para Gunnell, a orientação pragmática ditava que a Ciência Social americana produzisse soluções que "funcionassem" para problemas políticos concretos, e não teorias que fossem epistemologicamente coerentes ou filosoficamente informadas. A miopia dos imigrantes impediu-os de enxergar a relação umbilical que unia o empiricismo positivista praticado pela Ciência Política a um compromisso absoluto com o liberalismo democrático. Gunnell insiste em que a defesa da neutralidade em relação a valores não deve ser entendida como um relativismo moral absoluto. Pelo contrário, a defesa da neutralidade só foi possível porque havia um entendimento tácito de que a Ciência Política como um todo estava limitada ao campo da democracia liberal e, portanto, comprometida com seus valores básicos.

Contudo, apesar de equivocada, a crítica elaborada pelos intelectuais imigrantes surtiu efeitos que, segundo Gunnell, foram nefastos para o futuro da Ciência Política nos EUA. Sentindo a autoridade de seu saber ameaçada, os cientistas políticos lançaram a behavioral revolution, um novo esforço de produção de uma Ciência Política objetiva aos moldes das Ciências Naturais ${ }^{1}$. Um

\footnotetext{
1 A behavioral revolution, expressão que pode ser traduzida como "revolução comportamentalista", foi um movimento de crítica e revisão da Ciência Política americana iniciado nos anos 50, e que rapidamente se tornou hegemônico dentro dos meios acadêmicos daquele país. O livro The Political System de David Easton (EASTON, 1953) contém o
} 
dos pontos programáticos da behavioral revolution era a separação da Ciência Política verdadeiramente científica da história do pensamento político e das teorias políticas normativas (EASTON, 1953). Na prática, essa proposta levou à criação da teoria política como sub-área da Ciência Política, uma solução institucional que, segundo Gunnell, acabou causando o isolamento da teoria política das questões práticas mais candentes.

Gunnell conta que, antes da behavioral revolution, não havia distinção entre teoria política e Ciência Política. Naquele período, os cientistas políticos se consideravam os descendentes modernos dos clássicos do pensamento político. Gunnell chega a argumentar que a idéia de uma tradição da história do pensamento político é de fato uma invenção da Ciência Política americana. Tudo isso se acabou com a behavioral revolution. A análise da literatura de Ciência Política produzida atualmente nos EUA mostra que textos de teoria política, sejam eles clássicos ou modernos, são literalmente ignoradas pela produção acadêmica das quatro sub-áreas mais "científicas" da Ciência Política: política americana, política comparada, relações internacionais e políticas públicas.

Uma vez isolada das outras sub-áreas da Ciência Política, a teoria política, segundo conta Gunnell, começou a ser "colonizada" pela filosofia política e pela metateoria, abandonando assim problemas políticos concretos e dedicando-se a questões abstratas como a da natureza do conhecimento e da ação política. Outros teóricos políticos concentraram-se no estudo da história do pensamento, disciplina vista por Gunnell como um culto ao antiquarianismo sem relevância política e, portanto, uma forma de fuga dos problemas concretos da política (GUNNELL, 1993).

Mas os efeitos nefastos não se limitam ao enquistamento da teoria política. Ao responder à ameaça imigrante com um novo projeto que pregava maior rigor científico, a Ciência Política também acabou por se envolver com questões epistemológicas e filosóficas. Os fundadores da behavioral revolution foram buscar no positivismo lógico do círculo de Viena os fundamentos para seu "novo" projeto de Ciência Política baseado na separação radical entre fatos e valores e na verificabilidade empírica das teorias. Ironicamente, quando do lançamento do movimento, na década de 50, o positivismo lógico já estava em franco declínio nos meios filosóficos. Desde então, a Ciência Política americana tem visitado a filosofia da ciência repetidas vezes em busca de um modelo definitivo que lhe proporcione o tão almejado, mas nunca alcançado, status científico ${ }^{2}$.

Segundo Gunnell, a behavioral revolution cometeu um erro ao confundir a filosofia das Ciências Naturais, e suas teorias sobre como a ciência opera, com a prática das Ciências Naturais em si. Cientistas naturais se preocupam com problemas teóricos concretos e não com a filosofia do fazer científico. Em contraposição, os cientistas políticos passaram a se ocupar mais e mais com questões de cunho metateórico, a tal ponto que quase todo livro de Ciência Política se inicia com uma digressão sobre os pressupostos do conhecimento científico nas Ciências Sociais, e/ou um debate teórico sobre a natureza dos fenômenos sociais em questão.

Gunnell afirma que, apesar do barulho, a proposta disciplinar avançada pela behavioral revolution não trazia nada de substantivamente novo do ponto de vista da adesão histórica da Ciência Política americana ao empiricismo e à separação entre fato e valor. Para Gunnell erram os que acreditam que também por detrás do radicalismo da behavioral revolution havia um relativismo moral total. Ainda de acordo com esse autor, como seus predecessores, os arquitetos desse movimento eram também partidários dos valores do liberalismo democrático americano. $\mathrm{Na}$ behavioral revolution, como anteriormente, o compromisso com a democracia era tão consensual que esse assunto sequer era tratado.

\footnotetext{
2 Foi com esse intento que Grabriel Almond apelou para Karl Popper em Clouds and Clouds (POPPER, 1979), Adam Przeworski para Carl Hempel em The Logic of Comparative Social Inquiry (PRZEWORSKI, 1970), Almond e David Truman para Thomas Kuhn (TRUMAN, 1965; ALMOND, $1966)$ etc. Os mais recentes exemplos são proporcionados por cientistas políticos como John S. Dryzek, e Stephen T. Leonard que, para escapar do ceticismo kuhniano e tornar compreensível a história da própria disciplina, emprestaram, mais uma vez, as teorias de filósofos da ciência de Imre Lakatos, Larry Laudan e Stephen Toulmin (DRYZEK \& LEONARD, 1988; FARR \& GUNNELL, 1990).

Para uma idéia mais completa do debate entre Kuhn, Lakatos e Toulmin ver os procedimentos do Colóquio Internacional em Filosofia da Ciência, ocorrido em Londres, em 1965, e publicados no livro Criticism and the Growth of Knowledge (LAKATOS \& MUSGRAVE, 1970).
} 
No entanto, o envolvimento da Ciência Política com questões de ordem epistemológica levou a um abandono da orientação pragmática anterior. Gunnell argumenta que, hoje, após muitas "revoluções" científicas, tanto cientistas políticos como teóricos políticos vivem encerrados na torre de marfim universitária, ocupados com questões e problemas que raramente ultrapassam os limites da profissão e, portanto, pouco têm a ver com a política.

O plano geral da "história" de Gunnell não difere muito da de Farr, Ricci, Seidelman e Harpham. Em todas essas narrativas há primeiro um momento de idílio romântico entre uma ciência verdadeiramente engajada no aperfeiçoamento das instituições políticas democráticas e liberais americanas, depois uma queda, um processo de desencanto, em que a profissionalização excessiva, seja ela causada por motivos externos ou internos à própria disciplina, acaba por afastar os cientistas políticos da política. $O$ primeiro problema que salta à vista nesse tipo de narrativa é uma certa confusão conceitual quanto à democracia. Esses autores não raro tratam o liberalismo e o republicanismo americano como sinônimos de democracia. Ao fazerem isso, confundem a democracia, como princípio normativo de alargamento da participação política, com a forma de governo real dos EUA. Em suma, reduzem o universal ao particular e o "dever ser" ao "ser". É nesse ambiente intelectual que declarações como a de Leonard $\mathrm{D}$. White são levadas a sério: "nós [cientistas políticos] temos o dever de educar o mundo de acordo com o estilo de vida americano e o espírito do governo americano, feito segundo a sua imagem" (EASTON \& GUNNELL, 1995). Qualquer semelhança com a frase "fazer o mundo livre para a democracia", ouvida todas as vezes que os EUA cometem atos de violência internacional, não é mera coincidência.

A versão mais caricata dessa operação ideológica é dada por Easton, Gunnell e Stein, quando tentam universalizar a suposta relação histórica entre Ciência Política e democracia no EUA, transformando-a em uma hipótese de trabalho a ser testada em diferentes nações do mundo. A única coisa que é de fato testada com esse procedimento é o quanto um determinado país se assemelha aos EUA, segundo a imagem gloriosa que os próprios cientistas políticos americanos têm de seu regime político e de sua Ciência Política. O chauvinismo dessa postura fica explícito no esforço de Gunnell em pôr a culpa do suposto declínio da Ciência Política nos imigrantes alemães. Só falta agora chamá-los de um bando de judeus ressentidos. Ironicamente, esse misto de patriotada e liberalismo só confirma os maiores temores dos intelectuais imigrantes.

\section{A OUTRA HISTÓRIA}

As narrativas históricas comentadas acima não são as únicas produzidas dentro da academia americana, mas são as do mainstream - um termo que os americanos usam para descrever o centro, o núcleo duro, a parte de maior aceitação, e portanto, mais importante de uma determinada atividade humana. $\mathrm{O}$ termo tem também a conotação conservadora de desacreditar as críticas à posição mainstream como algo marginal, radical e, portanto, menos relevante. A condição mainstream dessas narrativas podem ser comprovadas pelo exame do veículo de divulgação através do qual elas vieram a público. As principais contribuições de Farr, Gunnell, Dryzek e Leonard, Seidelman e Harpham foram todas publicadas em forma de artigo em The American Political Science Review ou em The Journal of Politics, os dois periódicos mais mainstream da Ciência Política americana. Em contraposição, as versões mais críticas da história da disciplina não conseguiram alcançar tal prestígio acadêmico.

Esse é o caso do texto American Political Science in its Postwar Political Context, de Terence Ball, um autor renomado que, não obstante, publicou esse texto somente como capítulo de livro e não como artigo ${ }^{3}$. Assim como Farr, Ball se propõe a entender a história da Ciência Política americana no contexto de suas relações com a política e a sociedade em geral. Suas conclusões, porém, são muito diferentes das de Farr. Ball afirma que a Segunda Guerra Mundial foi um importante divisor de águas na história da disci-plina. Até então a Ciência Política era

\footnotetext{
3 Segundo os critérios formais e informais praticados pela academia americana, a publicação de um artigo em periódico cuja seleção é baseada em pareceres de outros acadêmicos tem maior reconhecimento e prestígio do que a publicação de um capítulo de livro, cuja seleção, geralmente, depende somente da escolha do editor do livro. As instituições de fomento à pesquisa no Brasil recentemente adotaram um critério de financiamento semelhante, privilegiando os periódicos que utilizam a avaliação por pareceristas em detrimento daqueles que restringem a escolha de artigos à comissão editorial.
} 
sustentada basicamente por recursos de instituições privadas. Com a entrada dos EUA no conflito, os cientistas sociais deixaram o confinamento da cátedra para se engajarem no esforço de guerra. A orientação behaviorista e empiricista da Ciência Política, que precede em muito a behavioral revolution, foi posta a serviço da política de guerra. Cientistas políticos e sociólogos dedicaram-se a estudar o comportamento e valores dos soldados, propaganda e alistamento militar, relações de raça na corporação militar, os efeitos sociais de bombardeios em populações civis etc. (BALL, 1993).

Com o fim do conflito, os cientistas políticos voltaram à academia, mas a experiência de guerra transformou sua atitude em relação à profissão e às relações entre academia e política. Ball diz que eles se tornaram "severos realistas com um senso sóbrio das possibilidades e limitações da política". Esse sobriedade se traduziu, do ponto de vista da prática disciplinar, em um maior interesse por questões relacionadas ao comportamento político concreto e, conseqüentemente, na rejeição de modos de pensar mais conceituais, inquisitivos e abstratos, próprios da teoria política e da filosofia. Harold Laswell, um dos cientistas políticos mais influentes dessa geração, usou o termo "policy sciences" para se referir à disciplina ${ }^{4}$. Foi com esse espírito que nasceu, segundo Ball, a behavioral revolution.

Ball chama a atenção para o fato de que esse movimento intelectual aconteceu ao mesmo tempo em que a guerra "quente" dos campos de batalha foi substituída pela guerra fria das trincheiras ideológicas. No novo contexto da manipulação de corações e mentes, os cientistas políticos se mostrariam ainda mais úteis. Mas essa utilidade social só poderia tornar-se realidade com o financiamento consistente das atividades acadêmicas. Como vantagem a seu favor, os cientistas políticos contavam com os contatos dentro do governo que haviam feito durante a guerra. Porém, a classe política e a opinião pública em geral desconfiavam da utilidade das Ciências Sociais, e viam a academia como um antro de radicais e esquerdistas 5 .

Através da análise dos depoimentos dados à comissão parlamentar que analisou a criação da Divisão para as Ciências Sociais na Fundação Nacional de Ciência (National Science Foundation), Ball mostra o esforço dos cientistas políticos para legitimar sua atividade e a resistência parlamentar em aceitar aqueles argumentos. Os congressistas americanos compreendiam bem a utilidade do investimento público em pesquisas no campo das Ciências Naturais para o esforço da Guerra Fria afinal de contas, este gerava frutos concretos. Porém, esses mesmos políticos tinham mais dificuldade em enxergar a mesma utilidade nos conhecimentos produzidos pelas Ciências Sociais. Como resposta, os cientistas sociais intensificaram a pregação cientificista, tentando mostrar que havia apenas uma diferença de grau entre o conhecimento produzido pelas Ciências Naturais e aquele produzido pelas Ciências Sociais. Ao mesmo tempo, esses mesmos acadêmicos defenderam a utilidade do conhecimento produzido pelas Ciências Sociais como forma de controle social, tão ou mais necessária quanto o controle de novas tecnologias proporcionado pelo avanço das Ciências Naturais.

A ênfase na tecnificação das Ciências Sociais foi bem recebida pelos órgãos governamentais e instituições privadas de fomento à pesquisa. Já em 1947, o Presidente do Conselho de Pesquisa em Ciências Sociais (Social Science Research Council), Pendleton Herring, declarava: "As Ciências Sociais necessitam enormemente da formação de profissionais competentes que possam usar dados sociais na cura dos males sociais, como médicos, que usam informações científicas para curar os males do corpo [...] O termo 'técnico’ em Ciências Sociais designa um indivíduo com treinamento profissional para aplicar os fatos, generalizações, princípios, leis e fórmulas descobertas pela pesquisa em Ciências Sociais às situações práticas [...] Engenharia social é a aplicação do conhecimento de fenômeno sociais a pro-

\footnotetext{
5 Em uma passagem do texto de tom bastante humorístico, Ball cita um Deputado do estado de Ohio que, ao discursar contra a criação de uma divisão para as Ciências Sociais na Fundação Nacional de Ciência (National Science Foundation) em 1946, refere-se aos cientistas sociais como um "bando de mulheres de cabelos curtos e homens de cabelos compridos se intrometendo na vida alheia” (BALL, 1993).
}

\footnotetext{
4 A palavra "policy" em inglês significa "princípio de ação", "procedimento", ou ainda "política” em português, como na expressão "políticas públicas” (public policy). O sentido que Laswell quis dar ao usar a expressão foi o de indicar que o papel da Ciência Política é produzir conhecimentos úteis à criação e aperfeiçoamento de políticas públicas.
} 
blemas específicos" (idem).

Em 1954, já em plena behavioral revolution, a Divisão para as Ciências Sociais da Fundação Nacional de Ciência foi finalmente criada. O tipo de pesquisa proposto pelos behavioristas era baseado na técnica de survey, que, por despender muitas horas de trabalho de coleta e análise de dados, necessitava de um grande aporte de recursos e estrutura institucional. Conseqüentemente, os acadêmicos que praticavam esse tipo de Ciência Política tornaram-se altamente dependentes das fontes de financiamento, privadas e públicas, a tal ponto que é difícil contar a história da behavioral revolution sem notar que a Fundação Ford esteve umbilicalmente envolvida com o financiamento das pesquisas e com a promoção dos acadêmicos desse movimento ${ }^{6}$. Com a relação de dependência, nota Ball, veio o controle e a seleção dos temas de pesquisa. Por sua vez, os cientistas políticos também passaram a deixar de lado temas controversos que pudessem ser recebidos com desconfiança pelas fontes de financiamento.

Ball nota que por trás da rejeição aparente de julgamentos de valor há na produção intelectual dos behavioristas uma tendência para enaltecer uma versão conservadora do liberalismo americano e, ao mesmo tempo, caracterizar o comunismo como uma patologia psicológica e social. Guiados pelo imperativo da glorificação do modo de vida e forma de governo americanos, os cientistas políticos produziram diagnósticos que tentavam mostrar que mesmo os aspectos mais problemáticos da política americana eram de fato virtudes. Os exemplos mais famosos, e infames, desse esforço intelectual são a adoção quase generalizada de uma teoria democrática de elites, e a "descoberta" de que a falta de participação popular é de fato uma virtude democrática. Ball conclui que "a Ciência Política fez uma contribuição valorosa ao arsenal americano da Guerra Fria" (idem).

Julgando pelas promessas e expectativas que alimentou quanto ao rigor disciplinar, a behavioral revolution não foi bem-sucedida. Sua capacidade

\footnotetext{
6 Segundo estimativas feitas por Albert Somit e Joseph Tanenhaus, durante as décadas de 40 e 50 a Fundação Ford foi responsável por $90 \%$ do financiamento privado de pesquisas em Ciência Política nos EUA (SOMIT \& TANENHAUS, 1967).
}

de explicação e previsão falharam mesmo nas áreas em que mais se investiram recursos: modernização e desenvolvimento de países de Terceiro Mundo, teoria da revolução, estabilidade política, e, finalmente, o estudo do regime soviético - o seu mais estrondoso fracasso. Paradoxalmente (ou não), esse mau desempenho disciplinar não se refletiu na capacidade dos cientistas políticos de financiar suas pesquisas, pois essa só cresceu durante toda a Guerra Fria e depois.

\section{EVIDÊNCIAS EM FAVOR DA VERSÃO ALTERNATIVA}

A disparidade entre a versão de Ball e as dos outros autores não pode ser ignorada. Ball evita a glorificação chauvinista que assume como premissas, reproduzidas com mais ou menos intensidade nas outras narrativas, de um passado idílico de engajamento dos cientistas políticos com o aperfeiçoamento da democracia americana, um vínculo inelutável entre a Ciência Política americana e a defesa da democracia, e a identificação imediata do sistema político americano com "a democracia". Além do mais, as outras histórias tendem a dramatizar um estado de crise da Ciência Política no pós-guerra, quando a disciplina perde relevância social e se afasta da política real. Ball mostra que, de fato, o contrário aconteceu. Durante a Guerra Fria, a Ciência Política ganhou uma relevância que nunca teve, servindo de aparelho ideológico do Estado americano. Não podemos subestimar a importância da Guerra Fria como fator de coesão política e propaganda nos EUA desse período. Nesse contexto, os imperativos da guerra foram freqüentemente colocados acima de questões relativas à democracia.

Além disso o argumento apresentado por Gunnell, segundo o qual o pragmatismo é capaz de resolver a contradição entre positivismo científico e relativismo moral através da limitação do debate ao âmbito da democracia liberal, deve ser problematizado. John Dewey, o mais ilustre filósofo político pragmatista, defende que, em uma sociedade democrática, as Ciências Sociais deveriam ser interpretativas. A diversidade característica das sociedades democráticas traduz-se em uma diversidade de perspectivas que geram diferentes interpretações dos assuntos politicamente relevantes. Para Dewey, a resolução desses conflitos de opinião deve dar-se no embate público e não no gabinete do especialista. Conseqüentemente, na democracia não há lugar para a auto- 
ridade científica positivista sobre a política. Dewey argumenta que as Ciências Sociais positivistas acabam facilmente convertendo-se em propaganda estatal, isso é, em ferramenta de supressão da democracia. Ironicamente, apesar de ser reverenciado como um dos fundadores da Ciência Política americana, Dewey foi praticamente ignorado pelos cientistas políticos. Em artigo recente, James Farr escreve que a história da recepção da obra de Dewey pela Ciência Política americana é a história de um não-ser, de algo que não aconteceu (FARR, 1999). Em outras palavras, o imperativo de se produzir uma Ciência Política positivista foi mais forte do que o chamado do pragmatismo de Dewey. Os problemas levantados por Dewey, na verdade, servem para questionar não a orientação pragmática dos cientistas políticos americanos, mas sua vocação democrática, que é dada gratuitamente por grande parte dos historiadores da Ciência Política examinados acima.

Infelizmente, a narrativa de Ball parece confirmar os temores de John Dewey. Dewey também nos ajuda a começar a responder à seguinte pergunta, somente formulada por Ball: se, do ponto de vista estritamente "científico", a Ciência Política americana fracassou, como se explica o sucesso na obtenção crescente de recursos para a pesquisa? A hipótese mais provável, já ventilada acima, é a de que a produção dessa ciência da política serviu de propaganda do Estado. Mas essa resposta é apenas parcialmente correta. O Estado americano não foi o único cliente das Ciências Sociais nesse período, apesar de talvez ter sido o maior. As fundações privadas tiveram um papel de destaque no fomento à pesquisa em Ciências Sociais naquele país, durante todo o período da Guerra Fria ${ }^{7}$. Não podemos nos esquecer também de que a maior parte do sistema universitário americano, incluindo os centros de pesquisa mais prestigiosos, são privados. Uma série de trabalhos atestam as perseguições a esquerdistas e a indivíduos ideologicamente "suspeitos" promovidas dentro das universidades americanas (SANDERS, 1979; RICHARDS, 1986; SCHRECKER, 1986; WINKS, 1987; LOWEN, 1997; PRICE, 1998), assim como a influência dos poderes político e econômico na

\footnotetext{
7 Para uma discussão sobre o papel das fundações na seleção de temas de pesquisa e suas conseqüências políticas e acadêmicas, ver Berger (1995) e Horowitz (1971).
}

academia (CHOMSKY, 1968 e 1997; MELANSON, 1983; SILVA \& SLAUGHTER, 1984; SIMPSON, 1998) ${ }^{8}$. Em suma, o Estado não foi o único responsável pela produção e reprodução da Guerra Fria. Poderosos interesses privados também estavam por detrás desse projeto político.

A resposta à pergunta apresentada no início do parágrafo anterior, portanto, tem que ser feita traçando-se as ligações entre os interesses mais poderosos por trás do financiamento das Ciências Sociais e o conteúdo e função social do conhecimento produzido por essas disciplinas. Esse é um tema para anos de trabalho, que provavelmente não será feito. O impulso crítico e auto-crítico nas Ciências Sociais americanas é bem mais fraco e marginal que o chamado para a produção de mais conhecimento positivo. Seria ingênuo pensar que as fontes financiadoras investiriam em projetos cujo objetivo é desmascarar os interesses políticos por trás das políticas de fomento implementadas por elas próprias. ${ }^{9}$

Devemos notar também que os autores dessa literatura marginal de crítica ao mainstream das Ciências Sociais americanas raramente são cientistas políticos. Mas não é só no quesito do exercício reflexivo de crítica de sua própria prática que a Ciência Política é omissa. A falta de uma atitude de crítica à sociedade e política americanas é, sem dúvida, a característica mais preocupante dessa disciplina. É claro que uma coisa está intimamente ligada à outra, ou seja, a falta de reflexão crítica interna pode ser entendida como sintoma ou causa da falta de uma atitude política crítica.

Um exemplo caricato desse estado de coisas é

\footnotetext{
8 Com raras excessões, essa histórias começaram a vir a público depois do arrefecimento da Guerra Fria.

9 O pronunciamento do então presidente do Conselho de Pesquisa em Ciências Sociais (Social Science Research Council), Kenneth Prewitt, em 1996, é um exemplo claro de como as fundações de fomento à pesquisa mudaram suas linhas temáticas com o fim da Guerra Fria, evitando, ao mesmo tempo, qualquer tipo de revisão crítica do material produzido. No texto, Prewitt defende que a estrutura disciplinar das Ciências Sociais baseada nos estudos de área funcionava durante a Guerra Fria; porém, com o seu fim, essa estrutura tornou-se ultrapassada, precisando ser substituída por uma organização que possibilite o estudo dos fenômenos transnacionais e globalizantes da atualidade (PREWITT, 1996). No mesmo período, as instituições de fomento americanas mais importantes passaram a implementar políticas similares.
} 
dado pelo trabalho dos jornalistas Russell Mokhiber e Robert Weissman, que juntos editam uma coluna chamada Focus on the Corporation, título que pode ser traduzido por "De olho nas grandes empresas". Aproveitando a disponibilidade, através da internet, de mais de mil artigos apresentados no encontro anual da Associação Americana de Ciência Política (APSA) do ano 2000, Mokhiber e Weissman resolveram procurar indícios da palavra "corporation" nos resumos dos trabalhos ${ }^{10}$. Somente dois resumos incluíam a palavra; a palavra "corporate" estava presente em 11 resumos. Tentaram então a palavra "business" e o resultado foi 23. Conclusão: aproximadamente apenas 3,6 \% dos trabalhos tratavam, de maneira central ou marginal, da questão do poder do capital.

Não contentes com os limites do material pesquisado, os autores decidiram examinar as teses de doutorado em Ciência Política defendidas nos últimos dois anos mediante a procura dos mesmos temas. Os resultados foram semelhantes. Apenas 75 dissertações usavam a palavra "corporation" no resumo, contra 43 que usavam a palavra "baseball", e 1008 que continham a palavra "war" (MOKHIBER \& WEISSMAN, 2000).

A premissa que está por trás do trabalho de Mokhiber e Weissman é que, em um país como os EUA, assim como na maioria do mundo, o capital tem um poder político imenso. Seria, portanto, coerente esperarmos que esse poder fosse assunto de um grande número de trabalhos em Ciência Política. Contudo, não é isso o que acontece.

O "achado" de Mokhiber e Weissman aponta para a conclusão de que um estudo crítico da história da Ciência Política americana deveria levar em conta não só o que foi escrito mas também o que não foi, isto é, as lacunas, os temas-tabu. Assim, poderemos entender quais os nexos ideológicos que possibilitaram, por exemplo, a teoria da modernização atribuir a causa do subdesenvolvimento a fatores culturais nacionais (JOHNSON, 1958; ROSTOW, 1960; LIPSET, 1967) e ignorar totalmente a inserção dessas nações no mais que centenário sistema capitalista

10 A palavra "corporation" em inglês atual significa, entre outras coisas, "grande empresa". Os americanos freqüentemente usam o termo "corporate power" ou "corporations" para se referirem a empresas gigantes e a conglomerados de capital. internacional, ou as teorias que explicam o surgimento do autoritarismo na América Latina (HUNTINGTON, 1968; O'DONNELL, 1973) fazerem vistas grossas à participação direta e indireta do governo americano na desestabilização dos regimes democráticos anteriores. Esta última é uma lacuna que interessa particularmente a nós, brasileiros.

\section{ESTRUTURA INSTITUCIONAL E VOCA- ÇÃO CONSERVADORA}

A idéia de uma ciência social positivista foi bastante criticada durante o século XX. Entre seus mais ilustres opositores estão a hermenêutica de inspiração gadameriana, a teoria crítica da escola de Frankfurt e Michel Foucault. Gadamer argumenta que nas sociedades contemporâneas há uma idolatria da ciência e da técnica, que leva as pessoas a deferir suas responsabilidades à autoridade do conhecimento científico. O discurso científico é monológico e, portanto, uma ameaça à base dialógica da política democrática, onde a reiteração interpretativa deve ser a norma. Essa ameaça é ainda mais séria naquelas ciências, crias do empiricismo britânico, que submetem os homens à lógica dos números e das leis universais (GADAMER, 1984). A tarefa da filosofia hermenêutica de Gadamer é proteger o espaço político da razão prática da dominação da autoridade do discurso técnico-científico (GADAMER, 1975).

A teoria crítica, em suas várias versões, tende a expor o caráter ideológico das Ciências Humanas. Max Horkeimer afirma que, negando a natureza dialética do conhecimento da coisas do homem, essas ciências produzem leis universais que contribuem para a sua reprodução e manutenção da sociedade capitalista burguesa. A teoria crítica, por outro lado, pretende quebrar com essa aparência e "produzir teorias que liberem os homens da reprodução mecânica do status social e acabe com a separação entre sujeito e objeto, entre conhecimento e ação" (HORKHEIMER, 1972). De maneira semelhante, Jürgen Habermas argumenta que o caráter ideológico das Ciências Sociais positivistas consiste no mascaramento de interesses concretos por um discurso do conhecimento que se apresenta na forma de leis universais imunes a questões de valor (HABERMAS, 1971)

Michel Foucault, por sua vez, mostra que por trás dos diferentes projetos de uma ciência do 
homem há a vontade de se submeter corpos e mentes a um controle disciplinar. Em seus estudos históricos, Foucault examina a ligação entre a produção de tecnologias de controle humano e o crescimento e sofisticação de instituições modernas como o Estado, as instituições penais, o exército, o hospício etc. (FOUCAULT, 1977, 1980, 1991).

Enquanto a hermenêutica de Gadamer não conseguiu penetrar no meio acadêmico americano de maneira significativa, Habermas e Foucault tornaram-se autores de grande sucesso nos EUA, atraindo um sem-número de seguidores e comentadores. As idéias desses autores penetraram no debate em disciplinas como História, Sociologia, Antropologia e estudos da cultura. A Ciência Política, contudo, parece ser praticamente imune a essas influências.

A estrutura institucional da Ciência Política americana atual parece ser a chave para compreender essa anomalia. Reflexões críticas como as de Habermas ou Foucault atingem a subárea de teoria política mas param por aí. Por estar isolada das outras sub-áreas, a teoria política acaba funcionando como uma barreira protetora que impede o contato das outras sub-áreas da Ciência Política com modos de pensar mais críticos. É dentro dos limites da teoria política que debates normativos são travados, sem terem qualquer consequiência para o resto da disciplina. Nos departamentos de Ciência Política das universidades americanas há uma distinção clara entre os "cientistas políticos" empiricistas das quatro subáreas e os teóricos políticos. Esse isolamento pode ser claramente comprovado pela análise da produção acadêmica de cada sub-área. Em uma pesquisa recente, examinando as referências bibliográficas de artigos publicados no ano de 2000 nos periódicos de Ciência Política de maior prestígio, os seguintes resultados foram encontrados (FERES, 2001) ${ }^{11}$ : a) de 110 artigos analisados, 93 não tinham qualquer referência bibliográfica que pudesse ser relacionada à teoria política; b) a média geral de citação de teoria política por artigo de Ciência Política era de 0,3.

\footnotetext{
11 Os periódicos analisados para a pesquisa foram The Journal of Politics, Politics and Society, Comparative Politics, Comparative Political Studies, International Organization e International Studies Quarterly.
}

Somente a título de ilustração, nos 110 artigos examinados, os nomes de Habermas e Foucault são citados somente uma vez, em um mesmo artigo.

\section{APRENDER SEM MACAQUEAR}

Fiquei positivamente impressionado com o último congresso da recém-criada Associação Brasileira de Ciência Política (ABCP). A diversidade temática era grande, e o vigor com que muitos se dedicavam a discutir problemas cruciais da sociedade e política brasileiras era no mínimo estimulante. Uma coisa, porém, deixou-me um pouco aborrecido, senão preocupado. Notei que alguns dos trabalhos limitavam-se a analisar aspectos da sociedade americana sem qualquer conexão com "realidades" brasileiras. Minha preocupação apenas aumentou ao constatar que a platéia, também formada por cientistas políticos, não raro se mostrava muito interessada no assunto. Não que essa atitude seja desconhecida. Todos sabemos da grande influência que, há décadas, as coisas da cultura americana exercem no Brasil. A necessidade de parecer americano e a vontade de ser americano são, para muitos, uma forma de escapar das frustrações de um Brasil que parece sempre ficar aquém das expectativas. Porém, como o estóico descrito por Hegel que se liberta no domínio do pensamento mas continua vivendo concretamente como um escravo, o americanófilo acrítico vive uma liberdade imaginária que é constantemente negada pelo fato de não estar nos EUA, não saber falar ou entender inglês corretamente, e não ter cidadania americana; em suma, de não poder realizar o ideal tão sonhado. Essa é a condição do colonizado cultural. Penso somente que nós, cientistas sociais e estudantes de filosofia, temos a obrigação de ser um pouco mais críticos em relação a esse assunto.

Esse artigo pretende ter mostrado que o estudo das coisas americanas não precisa ser uma fonte de alienação. Pelo contrário, ele pode ser usado para ajudar-nos a entender melhor os aspectos dessa colonização, pois o pior colonizado é aquele que ignora sua própria condição.

No tocante às relações acadêmicas, não podemos nos esquecer de que a imensa maioria da Ciência Política que se produz no mundo provém dos EUA. Com a exceção parcial da teoria da dependência e da Ciência Política de inspiração marxista, as outras teorias e tendências da Ciência Política foram criadas naquele país. Além disso, a 
academia americana produz Ciência Política sobre o Brasil, diretamente através dos brasilianistas, e indiretamente através dos latinoamericanistas ${ }^{12}$. Conseqüentemente, trabalhos escritos por brasileiros tendem a incorporar autores americanos ao debate. Mas, ao invés de tratarmos o debate acadêmico como uma troca de idéias desinteressada que ocorre em um espaço abstrato de discussão informada, devemos estar atentos ao alto grau de chauvinismo de grande parte da produção acadêmica americana ${ }^{13}$ e aos interesses políticos e econômicos por trás desses discursos "científicos". Não se trata aqui de combater chauvinismo com chauvinismo - afinal de contas, os fenômenos culturais mais originais e vigorosos da história brasileira nasceram da incorporação e mistura de elementos "estrangeiros" ao cabedal "nacional". Trata-se, sim, de manter uma atitude crítica frente a um tipo de discurso que se legitima através da armadilha retórica da veracidade factual.

Devemos reconhecer que a falta de especialização na academia brasileira, em comparação à alta fragmentação da academia americana, é, de fato, uma característica positiva que não deve ser descartada. Como mostra o exemplo americano, a separação da Ciência Política em especialidades isoladas em si mesmas, e das Ciências Sociais co-

\footnotetext{
12 A academia americana tem instituições desenhadas com a finalidade de se produzir conhecimento sobre outras regiões do mundo. Os estudos de área são agrupamentos multidisciplinares que se concentram no estudo de uma determinada região. A sub-área da Ciência Política que recebe o nome de política comparada inclui todo e qualquer trabalho de Ciência Política cujo objeto não são os EUA.

13 Uma caracterísica que, como vimos, afeta não só os cientistas políticos mas também os historiadores da Ciência Política.
}

mo um todo, contribui para o esvaziamento crítico do debate político e acadêmico.

O chauvinismo americano está por trás da crença em uma ciência social positivista e, ao mesmo tempo, democrática. Ele permite que essa ciência sobreviva sem a necessidade de criticar a si própria, e que sirva a interesses públicos e privados sem se perguntar se são de fato democráticos. Felizmente, devido à consciência que temos dos percalços de nossa história política, nós, brasileiros interessados no alargamento da democracia, talvez nunca tenhamos esse excesso de auto-confiança e, portanto, nunca devamos apostar cegamente em uma "Ciência" política democrática. Se nosso compromisso com a democracia é realmente sério, nosso compromisso com a Ciência deve ser bem relativo ${ }^{14}$.

Recebido para publicação em 4 de junho de 2001.

João Feres Jr. (jferes@att.net) é Doutorando em Ciência Política na City University of New York (CUNY), Mestre em Filosofia pela Universidade Estadual de Campinas (UNICAMP) e Mestre em Ciência Política pela CUNY.

\section{REFERÊNCIAS BIBLIOGRÁFICAS}

ALMOND, G. A. 1966. Political Theory and Political Science. American Political Science Review, v. 60, n. 4, Dec., p. 869-879.

ANCKAR, D. \& BERNDTSON, E. 1987. The
Evolution of Political Science : Selected Case Studies. International Political Science Review, v. 8 , n. 5 , p. $5-103$.

BALL, T. 1993. American Political Science in its 
Postwar Political Context. In : FARR, J. \& SEIDELMAN, R. Discipline and History : Political Science in the United States. Ann Arbor : University of Michigan Press.

BERGER, M. T. 1995. Under Northern Eyes : Latin American Studies and U.S. Hegemony in the Americas, 1898-1990. Bloomington : Indiana University Press.

CHOMSKY, N. 1968. American Power and the New Mandarins. New York : Pantheon.

(ed.). 1997. The Cold War and the University. New York : New Press.

DAHL, R. 1972. The Behavioral Approach in Political Science : Epitaph for a Monument to a Successful Protest. In : FARR, J. \& SEIDELMAN, R. Discipline and History : Political Science in the United States. Ann Arbor : University of Michigan Press.

DRYZEK, J. S. \& LEONARD, S. T. 1988. History and Discipline in Political Science. The American Political Science Review, v. 82, n. 4, p. 1245-1260.

EASTON, D. 1953. The Political System : an Inquiry into the State of Political Science. New York : Knopf.

EASTON, D. \& GUNNELL, J. G. (eds.). 1995. Regime and Discipline : Democracy and the Development of Political Science. Ann Arbor : University of Michigan Press.

FARR, J. 1988. The History of Political Science. American Journal of Political Science, v. 32, n. 4, p. 1175-1 195.

1999. John Dewey and American Political Science. American Journal of Political Science, v. 43, n. 2, p. 520-541.

FARR, J. \& GUNNELL, J. G. 1990. Can Political Science be Neutral? The American Political Science Review, v. 84, n. 2, p. 587-607.

FERES, J. J. 2001. Pragmatic Remarks on the Relevance of Political Theory to the Other Subfields of Political Science. Third annual SPTSA theory mini-conference. New York : City University of New York, Graduate Center.

FOUCAULT, M. 1977. Discipline and Punish: the Birth of the Prison. New York : Pantheon Books.
1980. Power/Knowledge: Selected Interviews and Other Writings. New York : Pantheon Books.

. 1991. The Foucault Effect : Studies in Governmentality. Chicago : University of Chicago Press.

GADAMER, H.-G. 1975. Hermeneutics and the Social Sciences. Cultural hermeneutics, n. 2, p. $307-316$.

. 1984. The Hermeneutics of Suspicion. In : SHAPIRO, G. \& SICA, A. Hermeneutics; Questions and Prospects. Amherst : University of Massachusetts Press.

GUNNELL, J. G. 1988. American Political Science, Liberalism and the Invention of Political Theory. American Political Science Review, v. 82 , n. 1 , p. $71-87$.

. 1993. The Descent of Political Theory: the Genealogy of an American Vocation. Chicago : University of Chicago Press.

HABERMAS, J. 1971. Knowledge and Human Interests. Boston : Beacon Press.

HORKHEIMER, M. 1972. Critical Theory. Selected Essays. New York : Herder and Herder.

HOROWITZ, I. L. (ed.). 1971. The Use and Abuse of Social Science. New Brunswick : E.P. Dutton.

HUNTINGTON, S. P. 1968. Political Order in Changing Societies. New Haven : Yale University Press.

JOHNSON, J. J. 1958. Political Change in Latin America. The Emergence of the Middle Sectors. Stanford : Stanford University Press.

LAKATOS, I. \& MUSGRAVE, A. (eds.). 1970. Criticism and the Growth of Knowledge. Cambridge : Cambridge University Press.

LIPSET, S. M. 1967. Elites in Latin America. New York : Oxford University Press.

LOWEN, R. S. 1997. Creating the Cold War University. Berkeley : University of California Press.

MELANSON, R. A. 1983. Writing History and Making Policy. The Cold War, Vietnam and Revisionism. New York : University Press of America. 
MOKHIBER, R. \& WEISSMAN, R. 2000. Study Power no More. Political Scientists Fail to Cover Corporate Power. San Francisco Bay Guardian.

O'DONNELL, G. 1973. Modernization and Bureaucratic-Authoritarianism : Studies in South American Politics. Berkeley : Institute of International Studies, University of California.

POPPER, K. R. 1979. Objective Knowledge : an Evolutionary Approach. New York : Oxford University Press.

PREWITT, K. 1996. Presidential Items. Items, v. 50, n. 1, March.

PRICE, D. H. 1998. Cold War Anthropology. Collaborators and Victims of the National Security State. Identities, v. 4, n. 3/4, p. 389430.

PRZEWORSKI, A. \& TEUNE, H. 1970. The Logic of Comparative Social Inquiry. New York : Wiley-Interscience.

RICCI, D. M. 1984. The Tragedy of Political Science. Politics, Scholarship and Democracy. New Haven : Yale University Press.

RICHARDS, T. F. 1986. The Cold War at Rutgers University : a Case Study of the Dismissals of Professors Heimlich, Finley, and Glasser. Graduate Program in Social and Philosophical Foundations. New Brunswick : Rutgers University.
ROSTOW, W. W. 1960. The Stages of Economic Growth : a Non-Communist Manifesto. New York : Cambridge University Press.

SANDERS, J. 1979. Cold War on the Campus : Academic Freedom at the University of Washington, 1946-64. Seattle : University of Washington Press.

SCHRECKER, E. W. 1986. No Ivory Tower. McCarthyism and the Universities. New York : Oxford University Press.

SILVA, E. T. \& SLAUGHTER, S. A. 1984. Serving Power. The Making of the Academic Social Science Expert. New York : Greenwood Press.

SIMPSON, C. (ed.). 1998. Universities and Empire: Money and Politics in the Social Sciences during the Cold War. New York : The New Press.

SOMIT, A. \& TANENHAUS, J. 1967. The Development of American Political Science. Boston : Allyn and Bacon.

TRUMAN, D. B. 1965. Disillusion and Regeneration : the Quest for a Discipline. American Political Science Review, v. 59, n. 4, Dec., p. 865-873.

WINKS, R. 1987. Cloak and Gown. Scholars in the Secret War 1939-1961. New Haven : Yale University Press. 